Vol 1 Issue 2, Oktober 2019, Page. 1-11

ISSN (print): 2622-5859 ISSN (online):2622-0881

DOI: $10.31605 /$ jcis.v2i1

\title{
Komparasi Algoritma SAW, AHP, dan TOPSIS dalam Penentuan Uang Kuliah Tunggal (UKT)
}

\author{
Wawan Firgiawan ${ }^{1}$, Nuralamsah Zulkarnaim ${ }^{2}$, Sugiarto Cokrowibowo ${ }^{3}$ \\ ${ }^{1,2,3}$ Program Studi Informatika, Fakultas Teknik, Universitas Sulawesi Barat \\ Email: ${ }^{* 1}$ wawanfirgiawan9@gmail.com, ${ }^{2}$ nuralamsah@unsulbar.ac.id, \\ ${ }^{3}$ sugiarto.cokrowibowo@unsulbar.ac.id
}

\begin{abstract}
Abstrak
UKT mahasiswa mempunyai kelompok yang berbeda-beda, dimana tiap kelompok mempunyai persentase masing-masing yang sudah ditetapkan oleh pemerintah berdasarkan ekonomi mahasiswa. Tidak adanya standarisasi yang jelas dalam penentuan UKT menuai banyak problem. Pendekatan pengambil keputusan atau disebut Decision Support Systems (DSS) akan membantu dalam pengambilan keputusan terhadap UKT mahasiswa yang akurat. Tujuan dari makalah ini ingin membandingkan 3 metode Multicriteria Decision Analysis, yaitu menggunakan metode Simple Additive Weighting (SAW), metode Technique for Order Preference by Similarity to Ideal Solustion (TOPSIS) serta metode Analitical Hierarcy Process (AHP) yang digunakan dalam pengambilan keputusan penentuan UKT mahasiswa sesuai dengan kriteria untuk menentukan metode yang relevan akan permasalahan tersebut. Penentuan skala dan pembobotan dalam setiap metode akan mempengaruhi hasil yang diperoleh oleh masing-masing kriteria. Dari hasil komparasi dari 3 metode yaitu SAW, TOPSIS, dan AHP diperoleh bahwa AHP mempunyai nilai rata-rata yang mendekati nol yaitu dengan nilai 0,10, sedangkan TOPSIS mempunyai rata-rata yaitu 0,44 dan SAW sendiri dengan nilai rata-rata 0,53 sehingga AHP merupakan metode yang terbaik digunakan dalam penentuan UKT.
\end{abstract}

Kata Kunci - Penentuan UKT, SAW, TOPSIS, AHP

\begin{abstract}
UKT students have different groups, where each group has a percentage of each that has been determined by the government based on student economics. There is no clear standardization in the UKT election which is to reap a lot of problems. Decision-making decisions or so-called Decision Support Systems (DSS) will help in making decisions towards students UKT more objectively and accurately. The purpose of this paper is to compare the 3 methods of Multi Criteria Decision Analysis, which uses the Simple Additive Weighting (SAW) method, the Engineering method for Order Preference with Similarities with Ideal Solustion (TOPSIS) and the Analytical Hierarchy Process (AHP) method to determine student UKT according to criteria to determine the relevant method for the problem. Determination of scale and weighting in each method will affect the results obtained by each criterion. From the results of the comparison of 3 methods, namely SAW, TOPSIS, and AHP, it was found that AHP had an average value close to zero with a value of 0.10, while TOPSIS has an average of 0.44 and SAW itself with an average value of 0,53 , so that $A H P$ is the best method used in determining UKT.
\end{abstract}

Keywords - Determination of UKT, SAW, TOPSIS, AHP 


\section{LATAR BELAKANG}

Proses pengambilan keputusan bukanlah hal yang mudah, ini merupakan masalah yang dihadapi setiap hari oleh semua orang dalam melakukan aktivitasnya. Hal tersebut muncul akibat banyaknya alternatif terhadap keputusan yang akan kita ambil berdasarkan pertimbangan yang kita lakukan untuk menghasilkan keputusan terbaik. Dalam beberapa kasus, banyaknya pilihan atau alternatif yang tersedia membuat kita jadi kebingungan atau sulit dalam mengambil keputusan terhadap permasalahan tersebut. Perkembangan teknologi saat ini dapat kita manfaatkan untuk memberikan rekomendasi atau pertimbangan keputusan yang kita ambil.

Pada penelitian ini penulis memilih masalah penentuan Uang Kuliah Tunggal (UKT) yang merupakan biaya kuliah yang ditanggung setiap mahasiswa khususnya Perguruan Tinggi Negeri (PTN) di Indonesia. Sejak dikeluarkannya Permendikbud Nomor 55 Tahun 2013 tentang UKT menimbulkan beberapa problem dikarenakan berbagai fakor terhadap penetapan UKT mahasiswa, sehingga banyak mahasiswa merasa keberatan akan UKT yang dibebankan dan beberapa mahasiswa terpaksa putus kuliah akibat tidak mampu membayar UKT. Penggunaan Decision Support System (DSS) akan membantu proses penentuan UKT bagi mahasiswa sehingga penetapan UKT dapat memberikan penilaian yang objektif.

Adapun beberapa Metode yang dapat digunakan dalam penetapan UKT seperti Multiple Criteria Decision Making (MCDM). Beberapa contoh MCDM adalah Simple Additive Weighthing (SAW), Technique for Order Preference by Similiarity to Ideal Solution (TOPSIS), PROMENTHEE, dan Analytical Hierarchy Process (AHP) [1].

Dalam penelitian ini akan membandingkan antara 3 metode yang sering digunakan di beberapa kasus penentuan keputusan yaitu Simple Additive Weighthing (SAW), Technique for Order Preference by Similiarity to Ideal Solution (TOPSIS), dan Analytical Hierarchy Process (AHP). Disini kita akan menentukan akurasi dari ketiga metode tersebut dalam penetapan UKT sehingga menghasilkan rekomendasi metode yang relevan untuk permasalahan tersebut.

\section{TINJAUAN PUSTAKA}

\subsection{Uang Kuliah Tunggal}

Uang Kuliah Tunggal (UKT) berdasarkan peraturan Menteri Pendidikan dan Kebudayaan Republik Indonesia nomor 55 tahun 2013 merupakan sebagian biaya kuliah tunggal yang ditanggung setiap mahasiswa berdasarkan kemampuan ekonominya. Penentuan UKT juga terdiri dari beberapa kelompok atau golongan yang ditentukan berdasarkan kemampuan ekonomi masyarakat [2].

\subsection{Sistem Pendukung Keputusan}

Sistem Pendukung Keputusan (SPK) atau disebut juga Decision Support System (DSS) merupakan suatu metodologi yang digunakan untuk mendukung pengambilan keputusan. Sistem 
pendukung keputusan sebaiknya bersifat fleksibel, interakif, dan dapat diadaptasi untuk mendukung solusi terhadap masalah manajemen spesifik yang tidak terstruktur. Sistem pendukung keputusan biasanya menggunakan berbagai model dan dibangun melaui proses interaktif dan iteratif sehingga dapat berjalan sesuai dengan harapan. Sistem pendukung keputusan sekarang ini sudah banyak dikembangkan dan dapat digunakan di PC maupun aplikasi atau web untuk digunakan banyak orang meski berada pada lokasi yang berbeda [3].

\subsection{Simple Additive Weighting}

Simple Additive Weighting (SAW) merupakan salah satu metode yang sering digunakan dalam sistem pengambil keputusan. Metode SAW dikenal juga dengan penjumlahan terbobot. SAW juga adalah salah satu metode untuk pengambilan keputusan multi-atribut atau Multi Attribute Decision Making (MADM). Algoritma ini banyak digunakan dalam beberapa kasus untuk menentukan alternatif terbaik dari banyak alternatif yang ada [4].

Konsep dasar metode SAW adalah mencari bobot yang diperoleh dari peringkat kinerja setiap alternatif terhadap semua kriteria yang ada. Dalam metode SAW juga perlu proses normalisasi matriks keputusan yang menjadi skala yang berimbang antara semua kriteria. Dalam menentukan hasil perhitungan dengan metode SAW, terdapat 2 atribut yaitu dengan terlebih dahulu menentukan sifat dari masing-masing kriteria yang ada, apakah bersifat benefit atau bersifat cost [1]. Adapun tahapan dalam menggunakan metode SAW adalah sebagai berikut [5]:

1. Normalisasi matriks disesuaikan dengan jenis atribut sehingga matriks yang dinormalisasi akan diperoleh perhitungan normalisasi matriks yang ditunjukkan pada persamaan (1).

$$
r_{i j}=\left\{\begin{array}{lr}
\frac{x_{i j}}{\operatorname{maxx}_{i j}} & , j i k a j \text { adalah atribut keuntungan (benefit) } \\
\frac{\operatorname{minx}_{i j}}{x_{i j}} & , j i k a j \text { adalah atribut biaya (cost) }
\end{array}\right.
$$

$$
\begin{array}{ll}
\operatorname{dimana}: & \\
r_{i j} & =\text { matrix dinormalisasi }[\mathrm{i}][\mathrm{j}] ; \\
x_{i j} & =\text { matriks keputusan }[\mathrm{i}][\mathrm{j}] ; \\
i & =1,2,3, \ldots, \mathrm{m} ; \\
j & =1,2,3, \ldots, \mathrm{n} ; \\
\max _{i} & =\text { nilai tertinggi dari setiap kolom matriks. }
\end{array}
$$

2. Menghitung nilai alternatif terakhir, hal ini dapat ditemukan menggunakan persamaan (2).

$$
V_{i}=\sum_{j=1}^{n} W_{i} r_{i j}
$$


dimana :

$V_{i} \quad=$ nilai akhir dari alternatif;

$W_{i} \quad=$ nilai bobot;

$r_{i j} \quad=$ nilai yang dinormalisasi;

$n \quad=$ jumlah kriteria.

3. Melakukan pengurutan data berdasarkan nilai preferensi setiap alternatif yang diperoleh dari proses sebelumnya, yang dimana menjadi hasil terbaik dari penilaian.

\subsection{Technique for Order Preference by Similarity to an Ideal Solution (TOPSIS)}

Metode Technique for Order Preference by Similarity to an Ideal Solution (TOPSIS) adalah salah satu metode pengambilan keputusan multi-kriteria atau Multi Criteria Decision Making (MADM) yang pertama kali diperkenalkan oleh Hwang dan Yoong. Metode ini merupakan metode yang banyak digunakan untuk menyelesaikan pengambilan keputusan dalam berbagai permasalahan. TOPSIS memiliki konsep dimana alternatif yang terpilih merupakan alternatif terbaik yang memiliki jarak terpendek dari solusi ideal positif $(\mathrm{A}+)$ dan jarak terjauh dari solusi ideal negatif (A-) [1]. Adapun langkah-langkah untuk menggunakan metode TOPSIS, adalah sebagai berikut [6]:

1. Menentukan matriks keputusan yang ternormalisasi, dimana menggambarkan alternatif $(\mathrm{X})$ dan kriteria (n) ke dalam sebuah matriks, dimana $X_{\mathrm{ij}}$ adalah pengukuran pilihan dari alternatif ke-i dan kriteria ke-j. Matriks ini dapat dilihat pada persamaan (3).

$$
\mathrm{D}=\left[\begin{array}{llll}
X_{11} & X_{12} & \ldots & X_{13} \\
X_{21} & X_{22} & \ldots & X_{23} \\
X_{i 1} & X_{i 2} & \ldots & X_{x i j}
\end{array}\right]
$$

2. Membuat matriks $R$ yaitu matriks keputusan ternormalisasi Setiap normalisasi dari nilai $\mathrm{r}_{\mathrm{ij}}$ dapat dilakukan dengan perhitungan menggunakan persamaan (4).

$$
r_{i j}=\frac{x_{i j}}{\sqrt{\sum_{i=1}^{m} X_{i j}}}
$$

Dimana : $(i=1,2, \ldots, n ; j=1,2, \ldots, m)$

3. Membuat pembobotan pada matriks yang telah dinormalisasi, setiap kolom pada matriks $\mathrm{R}$ dikalikan dengan bobot-bobot $\left(\mathrm{W}_{\mathrm{j}}\right)$ untuk menghasilkan matriks pada persamaan (5). 


$$
\mathrm{D}=\left[\begin{array}{ccc}
W_{1} r_{11} & W_{1} r_{12} & W_{n} r_{n} \\
W_{2} r_{21} & \ldots & \ldots \\
W_{j} r_{m 1} & W_{j} r_{m 2} & W_{j} r_{m m}
\end{array}\right]
$$

4. Menentukan nilai solusi ideal positif dan solusi ideal negatif. Solusi ideal diumpamakan sebagai A+, sedangkan solusi ideal negatif diumpamakan sebagai A-. Persamaan untuk menentukan solusi ideal dapat dilihat pada persamaan enam (6).

$$
\begin{array}{ll}
\mathrm{A}+ & =\left(W_{1}^{+}, W_{2}^{+}, \ldots, W_{j}^{+}\right) \\
\mathrm{A}- & =\left(W_{1}^{-}, W_{2}^{-}, \ldots, W_{j}^{-}\right)
\end{array}
$$

Dengan ketentuan,

$$
\begin{array}{ll}
W_{1}^{+} & \left(\max \mathrm{W}_{\mathrm{ij}}, \mathrm{jika} \mathrm{j}=\text { Keuntungan }\right) \mid\left(\min \mathrm{W}_{\mathrm{ij}}, \mathrm{jika} \mathrm{j}=\text { biaya }\right) \\
W_{1}^{-} & \left(\max \mathrm{W}_{\mathrm{ij}}, \mathrm{jika} \mathrm{j}=\text { Keuntungan }\right) \mid\left(\min \mathrm{W}_{\mathrm{ij}}, \mathrm{jika} \mathrm{j}=\text { biaya }\right)
\end{array}
$$

5. Kemudian menghitung Separation Measure. Separation Measure merupakan pengukuran jarak dari suatu alternatif ke solusi ideal positif $\left(S_{i}^{+}\right)$dan solusi ideal negatif $S_{i}^{-}$.

- Perhitungan solusi ideal positif dapat dilihat pada persamaan tujuh (7) :

$$
\begin{aligned}
& S_{i}^{+}=\sqrt{\sum_{i=1}^{n}\left(V_{i j}-V_{j}+\right)^{2}} \\
& \text { dengan } \mathrm{i}=1,2,3, \ldots, \mathrm{n} .
\end{aligned}
$$

- Perhitungan solusi ideal negatif dapat dilihat pada persamaan delapan (8) :

$$
S_{i}^{-}=\sqrt{\sum_{i=1}^{n}\left(V_{i j}-V_{j}-\right)^{2}}
$$

dengan $\mathrm{i}=1,2,3, \ldots, \mathrm{n}$.

6. Menghitung nilai preferensi untuk setiap alternatif. Untuk menentukan peringkatan tiaptiap alternatif yang ada maka perlu dihitung terlebih dahulu nilai referensi dari tiap alternatif. Perhitungan nilai preferensi dapat dilihat melalui persamaan tujuh. Setelah didapat nilai $C_{i}^{+}$, maka alternatif dapat diurutkan berdasarkan urutan $C_{i}^{+}$. Dari hasil diurutkan ini dapat dilihat alternatif terbaik yaitu alternatif yang memiliki jarak terpendek dari solusi ideal dan berjarak terjauh dari solusi ideal negatif.

$$
C_{i}^{+}=\frac{S_{i}^{-}}{S_{i}^{+}+S_{i}^{-}}
$$

dimana $0<\mathrm{Ci}+<1$ dan $\mathrm{i}=1,2,3, \ldots, \mathrm{m}$ (nilai $\mathrm{Ci}$ yang lebih besar menunjukkan prioritas). 


\subsection{Analytic Hierarchy Process (AHP)}

AHP merupakan suatu metode pendukung keputusan yang dikembangkan oleh Thomas L. Saaty [5] [7]. AHP merupakan metode untuk membuat urutan alternatif keputusan dan pemilihan alternatif terbaik pada saat pengambil keputusan dengan beberapa tujuan atau kriteria untuk mengambil keputusan tertentu. AHP akan menguraikan suatu masalah multi-kriteria yang kompleks menjadi suatu hierarki yang akan digunakan. AHP digunakan untuk mengorganisasikan informasi dan pertimbangan dalam memilih alternatif. Dengan menggunakan AHP suatu persoalan akan dipecahkan dalam suatu kerangka berpikir yang sistematis, sehingga memungkinkan dapat mengambil keputusan yang efektif terhadap persoalan [3] [8].

Untuk menyelesaikan permasalahan pengambilan keputusan menggunakan Analytic Hierarchy Process (AHP), harus memahami beberapa prinsip. Menurut Kusrini prinsip tersebut terdiri dari 4, yaitu [6]:

1. Mendefinisikan masalah dan menentukan solusi yang diinginkan, lalu menyusun hierarki dari permasalahan yang dihadapi. Penyusunan hierarki adalah dengan menetapkan tujuan yang merupakan sasaran sistem secara keseluruhan pada level teratas.

2. Menentukan prioritas elemen

a. Langkah pertama dalam menentukan prioritas elemen adalah membuat perbandingan pasangan, yaitu membandingkan elemen secara berpasangan sesuai kriteria yang diberikan.

b. Matriks perbandingan berpasangan diisi menggunakan bilangan untuk mempresentasikan kepentingan relatif dari suatu elemen terhadap elemen yang lainnya.

3. Sintesis

Pertimbangan-pertimbangan terhadap perbandingan berpasangan disintesis untuk memperoleh keseluruhan prioritas. Hal-hal yang dilakukan dalam langkah ini yaitu:

a. Menjumlahkan nilai-nilai dari setiap kolom pada matriks

b. Membagi setiap nilai kolom dengan total kolom yang bersangkutan untuk memperoleh normalisasi matriks.

c. Menjumlahkan nilai-nilai dari setiap baris dan membaginya dengan jumlah elemen untuk mendapatkan nilai rata-rata.

4. Mengukur konsistensi

Hal ini penting dilakukan untuk mengetahui seberapa baik konsistensi yang ada berdasarkan pertimbangan dengan konsistensi yang rendah. Hal-hal yang dilakukan dalam langkah mengukur konsistensi adalah :

a. Kalikan setiap nilai pada kolom pertama dengan prioritas relatif elemen pertama, nilai pada kolom kedua dengan prioritas relatif elemen kedua, dan seterusnya.

b. Jumlahkan setiap baris.

c. Hasil dari penjumlahan baris dibagi dengan elemen prioritas relatif yang bersangkutan. 
d. Jumlahkan hasil bagi di atas dengan banyaknya elemen yang ada, hasilnya disebut $K$ maks.

5. menghitung consistency indeks (CI) dengan rumus : $\frac{K m a k s-n}{n-1}$, dimana $\mathrm{n}=$ banyaknya elemen.

6. Menghitung consistency ratio $(\mathrm{CR})$ dengan rumus $=\frac{C I}{I R}$, dimana $\mathrm{IR}$ adalah indeks random konsistensi untuk memeriksa konsistensi hierarki. Jika nilainya lebih dari $10 \%$, maka penilaian data pertimbangan harus diulang atau diperbaiki. Namun jika rasio konsistensi $\left(\frac{C I}{I R}\right)$ kurang atau sama dengan 0,1, maka hasil perhitungan bisa dinyatakan benar. Adapun daftar indeks random konsistensi (IR) bisa dilihat pada tabel 1 .

\subsection{Euclidean Distance}

Euclidean Distance adalah jarak diantara dua buah objek atau lebih. Euclidean Distance dapat digunakan untuk mengukur kesamaan dari sebuah objek dengan objek yang lainnya. Dikatakan mempunyai kesamaan jika nilai dari obyek tersebut mendekati 0. Euclidean Distance diantara titik P $=(\mathrm{p} 1, \mathrm{p} 2, \ldots, \mathrm{pn})$ dan $\mathrm{Q}=(\mathrm{q} 1, \mathrm{q} 2, \ldots, \mathrm{qn})$ didefinisikan persamaan (10) sebagai berikut: [9]

$$
\text { Dist }=\sqrt{(\boldsymbol{p} 1-\boldsymbol{q} 1)^{2}+(\boldsymbol{p 2}-\boldsymbol{q} 2)^{2}+\ldots+(\boldsymbol{p n}-\boldsymbol{q n})^{2}}=\sqrt{\sum_{i=1}^{n}(p i-q i)^{2}}
$$

Tabel 1. Daftar Indeks Random Konsistensi (IR)

\begin{tabular}{cc}
\hline Ukuran Matriks & Nilai IR \\
\hline 1,2 & 0.00 \\
3 & 0.58 \\
4 & 0.90 \\
5 & 1.12 \\
6 & 1.24 \\
7 & 1.32 \\
8 & 1.41 \\
9 & 1.45 \\
10 & 1.49 \\
11 & 1.51 \\
12 & 1.48 \\
\hline
\end{tabular}

3. PEMBAHASAN DAN HASIL

\subsection{Data yang Digunakan}

Dalam penelitian ini, pengambilan data dibuat sendiri (Data Dummy) yang berjumlah 10 data yang akan digunakan. Data tersebut diberikan kode yaitu A1, A2, A3, ...., dan A10, dan 
menggunakan 4 kriteria atau atribut yaitu $\mathrm{C} 1$ adalah pendapatan orang tua, $\mathrm{C} 2$ adalah IPK, C3 adalah jumlah saudara, C4 adalah prestasi dimana masing-masing kriteria mempunyai bobot tertentu. Data tersebut ditunjukkan pada Tabel 2.

Tabel 2. Data Dummy dan Nilai Bobot masing-masing Kriteria

\begin{tabular}{ccccc}
\hline BOBOT & $\mathbf{0 , 4}$ & $\mathbf{0 , 3}$ & $\mathbf{0 , 2}$ & $\mathbf{0 , 1}$ \\
KODE & C1 & C2 & C3 & C4 \\
\hline A1 & 10 & 6 & 6 & 4 \\
A2 & 6 & 10 & 2 & 3 \\
A3 & 5 & 3 & 4 & 3 \\
A4 & 5 & 2 & 2 & 6 \\
A5 & 2 & 10 & 4 & 4 \\
A6 & 10 & 2 & 4 & 6 \\
A7 & 2 & 6 & 6 & 6 \\
A8 & 2 & 10 & 4 & 4 \\
A9 & 5 & 6 & 6 & 3 \\
A10 & 8 & 6 & 4 & 4 \\
\hline
\end{tabular}

Berdasarkan data yang ditunjukkan pada tabel 2, maka diperoleh hasil dari peringkat yang didapatkan dari tiga metode yang kemudian ketiga metode tersebut dikomparasi sehingga mendapat hasil perbandingan antara metode SAW, TOPSIS, dan AHP dalam penentuan Uang Kuliah Tunggal. Hasil dari perbandingan tersebut dilihat pada Tabel 3.

Tabel 3. Hasil Ranking Perbandingan dari SAW, TOPSIS, dan AHP

\begin{tabular}{cccc}
\hline Ranking & SAW & TOPSIS & AHP \\
\hline $\mathbf{1}$ & A1 & A1 & A1 \\
$\mathbf{2}$ & A10 & A10 & A6 \\
$\mathbf{3}$ & A2 & A2 & A10 \\
$\mathbf{4}$ & A6 & A6 & A2 \\
$\mathbf{5}$ & A9 & A9 & A9 \\
$\mathbf{6}$ & A5 & A5 & A5 \\
$\mathbf{7}$ & A8 & A8 & A8 \\
$\mathbf{8}$ & A7 & A3 & A7 \\
$\mathbf{9}$ & A3 & A7 & A3 \\
$\mathbf{1 0}$ & A4 & A4 & A4 \\
\hline
\end{tabular}


Pada tabel 3 telah diperoleh hasil perbandingan dari ketiga metode yang digunakan. Berdasarkan hasil yang diperoleh, terdapat nilai dan golongan UKT, dapat dilihat pada tabel 4.

Tabel 4. Nilai dan Golongan UKT

\begin{tabular}{cccc}
\hline SAW & TOPSIS & AHP & LEVEL \\
\hline 0,74 & 0,67 & 0,19 & \\
0,62 & 0,57 & 0,17 & UKT Golongan I \\
0,61 & 0,54 & 0,12 & \\
0,6 & 0,54 & 0,11 & \\
0,53 & 0,43 & 0,08 & \\
0,5 & 0,39 & 0,08 & UKT Golongan II \\
0,5 & 0,39 & 0,08 & \\
0,44 & 0,30 & 0,07 & \\
0,4 & 0,30 & 0,05 & UKT Golongan III \\
0,36 & 0,26 & 0,05 & \\
\hline
\end{tabular}

\subsection{Analisa Data menggunakan Euclidean Distance}

Analisis perbandingan menggunakan metode Euclidean Distance adalah untuk melihat metode mana yang paling optimal ditinjau dari rata-rata prioritas rangking pada ketiga metode yaitu SAW, AHP, TOPSIS seperti yang ditunjukkan pada tabel 5 dibawah ini.

Tabel 4: Analisa Euclidean Distance pada Nilai Rangking

\begin{tabular}{cccc}
\hline Ranking & SAW & TOPSIS & AHP \\
\hline 1 & 0,74 & 0,67 & 0,19 \\
2 & 0,62 & 0,57 & 0,17 \\
3 & 0,61 & 0,54 & 0,12 \\
4 & 0,6 & 0,54 & 0,11 \\
5 & 0,53 & 0,43 & 0,08 \\
6 & 0,5 & 0,39 & 0,08 \\
7 & 0,5 & 0,39 & 0,08 \\
8 & 0,44 & 0,30 & 0,07 \\
9 & 0,4 & 0,30 & 0,05 \\
10 & 0,36 & 0,26 & 0,05 \\
Rata-Rata & $\mathbf{0 , 5 3}$ & $\mathbf{0 , 4 4}$ & $\mathbf{0 , 1 0}$ \\
\hline
\end{tabular}




\subsection{Pembahasan}

Berdasarkan pada aturan Euclidean Distance untuk melihat metode mana yang paling optimal untuk digunakan yang ditinjau dari rata-rata prioritas dari rangking pada setiap data, maka dapat dikatakan bahwa Metode AHP merupakan metode yang paling optimal digunakan. Hal tersebut dikarenakan AHP memiliki nilai yang paling mendekati nilai nol yaitu dengan rata-rata 0,10. Kemudian disusul oleh metode TOPSIS dengan nilai 0,44 lalu kemudian metode SAW dengan nilai 0,53 . Hasil yang diperoleh dari ketiga metode yang digunakan memperlihatkan hasil yang tidak terlalu berbeda.

\section{KESIMPULAN}

Dari percobaan terhadap permasalahan penentuan Uang Kuliah Tunggal (UKT) dengan menggunakan metode SAW, TOPSIS, dan AHP, diperoleh bahwa metode AHP adalah metode yang baik digunakan dibandingkan 2 metode lainnya yang diuji. Pemilihan metode AHP sebagai solusi optimal yang disarankan melihat tingkat kedekatan jarak yang mendekati nol dibandingkan metode SAW dan TOPSIS yaitu dengan nilai rata-rata 0,10 . Kemudian alternatif yang kedua adalah metode TOPSIS dengan nilai 0,44 , kemudian metode SAW dengan nilai 0,53 .

\section{REFERENSI}

[1] M M D Widianta, R. T, D P S Setyohadi dan H Y Riskiawan, "Comparison if Multi-Criteria Decision Support Methods (AHP, TOPSIS, SAW \& PROMENTHEE) for Employee Placement," IJCST, no. Serie 953, 2018.

[2] K. P. d. Kebudayaan, Draft Permendikbud UKT, [1] Kementrian Pendidikan dan Kebudayaan, 2013.

[3] S. Sendana, H. A. Wibawa dan S. , "Sistem Penentuan Kelompok Uang Tunggal di Universitas Diponegoro Menggunakan Analytical Hierarchy Process,” 2014.

[4] A. Pranolo dan S. M. Widyastuti, "Simple Additive Weighting Method on Intelligent Agent for Urban Forest Health Monitoring," IEEE, 2014.

[5] A. Cahyapratama dan R. Sarno, "Application of Analytic Hierarchy Process (AHP) and Simple Additive Weighting (SAW) Methods In Singer Selection Process," IEEE, 2018.

[6] Kursini, Konsep dan Aplikasi Sistem Pendukung Keputusan, Yogyakarta: Andi Offset, 2017.

[7] S. Supraja dan D. P. Kousalya, "A Comparative Study by AHP and TOPSIS for the Selection of All Round Excellence Award," IEEE, 2016. 
[8] S. Cokrowibowo dan I. , "Analisis Penentuan Lokasi Outlet Menggunakan Sistem Informasi Geografis Dan Simple Additive Weighting, studi kasus: Outlet Kalla Automotive," dalam PROSIDING - Kajian Ilmiah Dosen Sulbar 2017, Majene, 2017.

[9] D. HIMAWAN, "Analisis Perbandingan Menggunakan Metode Ahp, Topsis, Dan Saw Dalam Studi Kasus Sistem Pendukung Keputusan Peminjam Yang Layak Bagi Lembaga Keuangan," Universitas Sumatera Utara, Medan, 2019.

[10] N. N. Putri, S. Edy dan M. A. Fauzi, "Sistem Pendukung Keputusan Penetapan Keringanan Uang Kuliah Tunggal (UKT) Menggunakan Metode Weighted Product - TOPSIS," ResearchGate, 2015. 